\title{
LEITURA CRÍTICA DO DISCURSO MULTIMODAL EM REPRESENTAÇÕES MIDIÁTICAS DAS MANIFESTAÇÕES DE JUNHO DE 2013
}

(Critical reading of the multimodal discourse in media representations of the demonstrations of June 2013)

\author{
Fábio Alexandre Silva Bezerra ${ }^{1}$ \\ Universidade Federal da Paraíba \\ Julianna Pereira Fagundes ${ }^{2}$ \\ Universidade Federal da Paraíba
}

\begin{abstract}
RESUMO
Os recursos verbais e visuais criam relações de poder, constroem identidades e difundem ideologias. Portanto, é importante desenvolvermos pesquisas que explorem esse potencial semiótico (VAN LEEUWEN, 2005) de construção de representações, especialmente considerando-se o desenvolvimento de projetos de multiletramentos. Nesse contexto de crescente importância dos estudos em multimodalidade (KRESS; VAN LEEUWEN, 2006), este artigo investiga representações das manifestações de junho de 2013 em capas de revistas nacionais com o intuito de desvendar sentidos construídos e discursos dominantes presentes nesse momento histórico (FAIRCLOUGH, 1995b, 2015[1989]; WODAK, 2004). Resultados gerais demonstram que as publicações analisadas, fazendo uso de estratégias narrativas, bem como de recursos interacionais e de composição, criam distanciamento entre o leitor e os fatos representados, possivelmente implicando em menor probabilidade de verem as manifestações como legítimas.
\end{abstract}

Palavras-chave: Multimodalidade. Capas de revista. Discurso. Manifestações

\begin{abstract}
Verbal and visual resources create power relations, construe identities and disseminate ideologies. Therefore, it is important to develop research exploring this semiotic potential (VAN LEEUWEN, 2005) for the construal of representations, especially when considering the development of multiliteracy projects. In this context of increasing relevance of multimodal studies (KRESS; VAN LEEUWEN, 2006), this paper investigates representations of the demonstrations of June 2013 in national magazine covers in order to uncover meanings construed and dominant discourses present in that historic moment (FAIRCLOUGH, 1995b, 2015[1989]; WODAK, 2004). Overall results show that, by making use of narrative strategies, as well as interactional resources and composition, the analyzed publications create distance between the reader and the represented facts, possibly implying lower probability of them seeing the demonstrations as legitimate.
\end{abstract}

Keywords: Multimodality. Magazine covers. Discourse. Demonstrations.

\footnotetext{
${ }^{1}$ Fábio Alexandre Silva Bezerra é professor do Departamento de Letras Estrangeiras Modernas (DLEM) e do Programa de Pós-Graduação em Linguística (PROLING) da Universidade Federal da Paraíba. É doutor em Língua Inglesa e Linguística Aplicada (Universidade Federal de Santa Catarina) e PhD em Linguística (University of Sydney). É coordenador do GEPLAM - Grupo de Estudos e Pesquisa em Linguística Sistêmico-Funcional, Análise Crítica do Discurso e Multimodalidade/Multiletramentos (UFPB/CNPq) e pesquisador do NUPDISCURSO - Núcleo de Pesquisa Texto, Discurso e Práticas Sociais (UFSC/CNPq). Desenvolve pesquisas em Análise Crítica do Discurso, Multimodalidade/Multiletramentos, Linguística Sistêmico-Funcional e Estudos de Gênero. Entre seus interesses de pesquisa, destacam-se representações de identidades, de discursos e de relações de poder no contexto escolar e na mídia, especialmente na TV, no cinema e em revistas. Contato: <fabes10@yahoo.com.br>.

${ }^{2}$ Julianna Pereira Fagundes é licenciada em Letras/Inglês pela Universidade Federal da Paraíba, tendo sido orientada pelo primeiro autor em projeto PIBIC intitulado "A leitura do texto verbal e da imagem na mídia contemporânea". Contato: <juliannapfagundes@hotmail.com>.
} 
Recebido em: outubro 2017

Aceito em: agosto 2018

DOI: 10.26512/les.v19i2.16890

\section{INTRODUÇÃO}

As transformações causadas pelo processo de globalização, bem como o advento das novas tecnologias, têm mudado a forma como textos e imagens são produzidos e consumidos. Tanto o texto verbal quanto o visual criam relações de poder, constroem identidades e difundem ideologias. Portanto, devido à necessidade de compreendermos como recursos semióticos (VAN LEEUWEN, 2005) além da linguagem verbal constroem sentidos, é importante desenvolvermos pesquisas que explorem esse potencial semiótico de construção de representações em textos multimodais (BEZERRA; NASCIMENTO; HEBERLE, 2010; HEBERLE, 2010; PROCÓPIO, SOUZA, 2010), principalmente quando pensamos no desenvolvimento de projetos de multiletramentos que capacitem professores/as e alunos/as a serem leitores/as mais proativos/as na sociedade contemporânea (BEZERRA, 2015, 2016; ROYCE, 2002; ROJO, 2009; ROJO; MOURA, 2012).

Nesse contexto de novas configurações textuais e modais, Kellner (2004), apud Kellner e Share (2008), destaca o impacto dos recursos midiáticos e o papel do/a professor/a de desenvolver a leitura crítica de seus/suas alunos/as, visto que "as novas tecnologias da comunicação são ferramentas poderosas que podem libertar ou dominar, manipular ou esclarecer" (p. 703). Segundo Kellner e Share (2008), os indivíduos precisam aprender a questionar criticamente os diferentes tipos de textos que os cercam para que possam exercer participação efetiva no meio em que vivem. Os autores defendem o letramento crítica da mídia como sendo

um imperativo para a democracia participativa, pois as novas tecnologias de informação e comunicação, associadas a uma cultura de mídia com base no mercado, fragmentaram, conectaram, convergiram, diversificaram, homogeneizaram, estabilizaram, ampliaram e remodelaram o mundo. Essas mudanças estão reconstruindo a maneira como as pessoas pensam e reestruturando as sociedades, nos níveis local e global. (p. 689-690)

Em face da relevância de se discutir o impacto da mídia na maneira como concebemos nossa realidade em sociedade, e utilizando conceitos da Análise Crítica do Discurso (ACD) propostos por Fairclough (2015[1989]) e da Gramática Visual de Kress e van Leeuwen (2006), que serão descritos na próxima seção, a presente pesquisa tem como objetivo geral analisar representações multimodais construídas em capas das três revistas semanais com maior tiragem no território nacional que tratam da cobertura das manifestações populares que se iniciaram em junho de 2013, movimento social que ficou conhecido como Manifestações dos 20 Centavos e que causou grande comoção e mobilização nacional. 
Tendo em vista o impacto dessas manifestações populares em nossa história recente, acreditamos ser importante analisarmos como os principais veículos da mídia impressa nacional as representaram. Tal investigação assume relevância especial ao considerarmos o argumento de Kellner (2003) ao afirmar que

os meios de comunicação dominantes (...) contribuem para nos ensinar como devemos nos comportar e o que (não) pensar, sentir, acreditar, temer e desejar. Consequentemente, o letramento midiático crítico é um recurso importante para indivíduos e cidadãos aprenderem a lidar com esse ambiente cultural sedutor. (p. 2)

Diante da imprescindibilidade dessa leitura crítica das representações midiáticas em nossa sociedade, a presente investigação destaca a importância de consideramos a necessidade de desenvolvermos novas práticas educativas a fim de viabilizar o desenvolvimento da "competência comunicativa multimodal” dos/as alunos/as (ROYCE, 2007; HEBERLE, 2010). Tais práticas implicam que não só a linguagem verbal, mas também a linguagem visual são elementos que criam significados e realidades. Portanto, o desenvolvimento da "competência comunicativa multimodal" pode possibilitar, a partir de projetos de multiletramentos, a formação crítica do/a aluno/a para que possa atuar na sociedade na qual está inserido/a de maneira mais consciente dos recursos de sentidos que estão a sua disposição e com os quais se depara diariamente.

Sendo assim, torna-se indispensável o trabalho com textos multimodais de grande circulação em nossa sociedade, dentre os quais podemos destacar as capas de revistas - produtos midiáticos de nosso cotidiano. Wodak (2004) assevera que

a linguagem da mídia de massa é detalhadamente analisada como um espaço de poder, de lutas, e também como um espaço onde a linguagem é aparentemente transparente. As instituições midiáticas costumam se considerar neutras por que acreditam que dão espaço para o discurso público, refletem os estados de coisas de forma desinteressada, e expressam as percepções e os argumentos dos jornalistas. (p. 231)

No intuito de relevar as diferentes maneiras como a mídia constrói representações específicas da realidade a partir de objetivos particulares por meio do uso de textos multimodais, mais marcadamente da imagem, um possível caminho para uma análise teoricamente embasada é a utilização das categorias de análise propostas pela gramática visual (KRESS; VAN LEEUWEN, 2006) ao descrever as imagens a partir de três campos semânticos organizados em três funções gerais: de representação, de interação e de composição. Cada uma destas funções descreve recursos que podem ser utilizados na produção de imagens e textos multimodais. 
A seguir, tais conceitos e categorias serão descritos, assim como será apresentado o suporte teórico da Análise Crítica do Discurso para a discussão dos resultados da análise multimodal com vistas à discussão dos discursos subjacentes nas capas analisadas.

\section{FundamentaÇão Teórica}

Desenvolvida por Kress e van Leeuwen (2006), a Gramática Visual é, em grande parte, uma extrapolação de conceitos teóricos da Gramática Sistêmico-Funcional (HALLIDAY; MATTHIESSEN, 2004), partindo do pressuposto de que as imagens apresentam estruturas sintáticas passíveis de análises, assim como ocorre com a linguagem verbal. Para discutir os resultados da análise multimodal, faz-se uso do suporte teórico da Análise Crítica do Discurso (ACD) proposta por Fairclough (2015[1989]), a qual permite que os discursos subjacentes presentes nos textos multimodais sejam revelados por meio de uma análise crítica.

\subsection{Gramática Visual}

Ao propor uma gramática visual para embasar teoricamente as análises de textos imagéticos, Kress e van Leeuwen (2006) propõem a organização dos significados potencialmente presentes nas imagens em termos de três domínios semânticos, quais sejam: representacional, interacional e composicional. Tais domínios ocorrem simultaneamente e criam padrões de experiências, relações sociais e posições ideológicas a partir das escolhas dos elementos imagéticos para construir a imagem.

Os significados representacionais correspondem às representações das experiências, e são organizados em dois campos ideacionais principais: representações narrativas e conceituais.

As representações narrativas são realizadas por meio de processos que inserem os participantes em eventos, ações. Tais processos são o acional, o reacional, o mental e o verbal. Os processos acional e reacional são identificados pela presença de um vetor, uma linha imaginária que dá a ideia de ação/movimento e direção, respectivamente. O processo acional pode ser transacional (quando há dois participantes representados e um vetor) ou não transacional (quando há um participante representado e um vetor). No processo reacional, o vetor é formado pelo olhar do participante representado. Também pode ser transacional ou não transacional; é transacional quando podemos identificar o objeto de contemplação do participante representado (PR), e não transacional quando não conseguimos identificar tal objeto. O processo mental é marcado pela presença de balões de pensamento, enquanto que o verbal é marcado por balões de fala. 
As representações conceituais, por sua vez, são composições visuais que representam os participantes em termos de classe/estrutura. Podem ser realizadas por processos classificacionais, analíticos e simbólicos. O processo classificacional categoriza os participantes, organizando-os em termos de taxonomias - explícita ou implícita. No processo analítico, a relação entre participantes é representada por meio da estrutura parte/todo. O processo simbólico, em turno, pode ser atributivo quando o conceito representado parte de uma característica do próprio PR - ou sugestivo - quando se sugere uma característica externa ao PR a partir de algum elemento adicional à representação, por meio, por exemplo, de manipulações nas cores, no tamanho e/ou na iluminação.

Os significados interacionais dizem respeito às relações entre os participantes representados (PR) e o leitor, e podem ser analisados a partir de quatro perspectivas: contato, atitude, distância social e poder. A relação de contato pode ser de demanda, quando o PR demanda atenção do leitor por meio de olhares convergentes, ou de oferta, quando tanto o PR, como o que ele olha são dispostos para observação do leitor, visto que os olhares do PR e do leitor não se encontram. A atitude diz respeito ao grau de envolvimento entre os participantes, e está relacionada ao ângulo em que o participante representado aparece para o leitor. Cria-se envolvimento a partir de um ângulo frontal ou distanciamento por meio de um ângulo oblíquo. A distância social determina o grau de distanciamento social entre os participantes da interação. Há os níveis de relação pessoal (close shot), social (medium shot) ou impessoal (long shot) entre participante representado e leitor. Podemos, ainda, analisar as imagens quanto às relações de poder estabelecidas entre leitor e participante representado. Quando o olhar do PR está no mesmo nível do olhar do leitor, dizemos que há igualdade de poder; quando o ponto de vista do PR é superior, temos que o poder é do PR em relação ao leitor; e, por fim, quando o ponto de vista do leitor é superior ao do PR, dizemos que o poder é do leitor em relação ao PR.

Os significados composicionais tratam da organização dos elementos imagéticos e são criados a partir da utilização de recursos visuais em três aspectos distintos: valor da informação, enquadramento e saliência. O valor da informação refere-se à posição dos elementos na composição da imagem. Temos as seguintes relações: dado/novo, em que as informações já conhecidas pelo leitor (dado) se localizam à esquerda, e as informações novas (novo) à direita; ideal/real, em que, na parte superior, aparece a sugestão ou promessa de algo ideal, que deve ser alcançado ou desejado, ao passo que, no campo inferior, vêm informações ligadas ao concreto, real; por fim, a relação centro/margem, em que as informações centrais são mais relevantes que as marginais.

O enquadramento é atingido por meio de molduras que enquadram ou não os elementos imagéticos. Quando os elementos que compõem a imagem estão enquadrados, dizemos que eles 
estão conectados; quando não enquadrados, estão desconectados. A saliência é utilizada como recurso para atrair a atenção do leitor por meio do uso de tamanho relativo, cor, contraste e posicionamento em primeiro ou segundo plano.

Em termos gerais percebe-se que, a partir da organização dos elementos que compõem o texto imagético, as imagens podem ser utilizadas para criar representações do mundo, bem como de processos internos, como pensamentos. Podem, também, estabelecer relações entre os participantes representados e o leitor, construindo, assim, sentidos adicionais, que variam entre questões de poder, atitude e proximidade, por exemplo. Além disso, as imagens, por si só, também criam sentidos composicionais ao organizarem os significados representacionais e interacionais em textos coerentes e coesos por meio de recursos tais como enquadramento e saliência.

\subsection{Análise Crítica do Discurso}

A Análise Crítica do Discurso (ACD) investiga a linguagem em uso dentro de um contexto social para revelar processos ideológicos, por exemplo - visto que é por meio da linguagem que agimos no mundo. Sendo assim, as práticas discursivas situadas, ou seja, o papel social que cada um de nós representa por meio da linguagem revela as nossas várias identidades e crenças (CALDASCOULTHARD, 2008) como atores sociais. Nesse sentido, Magalhães (2005) ressalta que "a ADC Análise do Discurso Crítica - estuda os textos e eventos em diversas práticas sociais, propondo uma teoria e um método para descrever, interpretar e explicar a linguagem no contexto sócio-histórico" (p. 3).

Assim, a ACD, partindo de textos específicos, preocupa-se em analisar práticas sociais e relações de poder que subjazem o discurso. A base para os estudos críticos da linguagem foi consolidada por Fairclough (1992a, 1992b, 1995a, 1995b, 2015[1989]), a partir da descrição, interpretação e explicação dos conceitos de discurso, hegemonia, ideologia e poder.

Segundo o autor, o discurso possui três dimensões, quais sejam: o texto em si, as práticas discursivas e as práticas sociais. Sendo assim, todo texto (seja ele falado ou escrito) transmite uma mensagem que, ao ser lida, promove interações de linguagem por meio da mobilização de práticas discursivas (texto-leitor/ouvinte). A prática social, por sua vez, é uma dimensão mais abrangente, que oportuniza considerações sobre relações de poder e de classe, por exemplo, a partir de discussões sobre ideologias que perpassam o texto em análise.

A compreensão sobre a maneira como as práticas sociais são constituídas a partir do discurso por meio de textos materiais específicos tem o potencial de possibilitar experiências de emancipação de indivíduos e/ou grupos que se encontrem em situação de opressão, bem como 
também viabiliza tomadas de consciência de outros grupos sobre seu papel na manutenção e/ou desconstrução de tais relações de dominação.

Citando Fairclough (1992a), Meurer (2005) descreve um aparato metodológico para fazer a análise crítica de um texto com base nessas três dimensões supracitadas: texto, práticas discursivas e práticas sociais. O texto (evento discursivo) é onde encontramos a descrição linguística, ou seja, é o nível de análise que mais se aproxima do significado literal do texto (léxico, gramática, coesão, estrutura). Já nas práticas discursivas, temos a interpretação do texto quanto a sua produção, distribuição e consumo. Nesse nível, são analisadas a força, coerência, intertextualidade e interdiscursividade que podem existir no texto. E, por fim, ao se analisar um evento discursivo a partir das práticas sociais, procura-se explicar e revelar ideologias e relações de poder/ hegemonia presentes no texto.

Com base nesse modelo tridimensional, vale destacar ainda que a ACD se organiza a partir de algumas concepções sobre linguagem, discurso, ideologia e relações de poder na sociedade (MEURER, 2005), quais sejam: a linguagem é vista como prática social, isto é, o discurso presente no texto influencia e é influenciado por quem o lê; a linguagem tem poder constitutivo, pois através dela identidades e realidades sociais são criadas; os textos trazem rotinas sociais, as quais são retratadas no discurso; relações de poder perpassam o discurso, sendo assim o poder hegemônico de uma classe social pode ser mantido por meio do mesmo; por trás da linguagem utilizada no discurso, há sempre ideologias e relações de poder subjacentes.

A ACD, portanto, além de ser uma teoria e um método de análise (WODAK, 2004), busca conscientizar os indivíduos quanto às relações existentes entre o discurso e as estruturas sociais, dando-se destaque, assim, a uma relação constitutiva de bidirecionalidade (MEURER, 2005).

Constata-se, dessa maneira, a evidente necessidade de considerarmos questões que vão além do nível textual quando queremos discutir relações de poder estabelecidas pela mídia. Em outras palavras, com base nos dados obtidos pela análise multimodal do texto, também deve haver a discussão das práticas discursivas nas quais esse mesmo texto analisado se insere, bem como das implicações ideológicas e das relações de poder estabelecidas por meio das práticas sociais com as quais ele se relaciona.

Nesse intuito analítico, descrevemos, a seguir, com maiores pormenores os procedimentos metodológicos que guiaram a presente pesquisa. 


\section{Metodologia}

Primeiramente, escolhemos as revistas Veja, Época e IstoÉ para análise, visto que essas publicações ocupam, nesta ordem, as três primeiras posições entre as revistas semanais mais vendidas no Brasil (IVC, 2013). É importante destacar, ainda, que o número de exemplares vendidos da revista Veja supera a soma dos exemplares vendidos das outras duas publicações. Um dos motivos para que a Veja tenha essa grande quantidade de cópias vendidas é o fato de que governos estaduais compram assinaturas para distribuírem exemplares para as escolas estaduais, sendo São Paulo um exemplo notório (STHEPHANOWITZ, 2013).

As capas escolhidas são de publicações de 2013 que tratam dos protestos populares que ocorreram principalmente nos meses de junho e julho, conhecidos como 'Manifestações dos 20 Centavos' e 'Jornadas de Junho' e inicialmente provocados pelo aumento das tarifas de transporte coletivo. Tais protestos já são reconhecidos como as maiores manifestações populares no Brasil desde o impeachment do ex-presidente Fernando Collor de Mello em 1992.

Foram selecionadas as capas das primeiras edições de cada uma das três revistas abordando, como já mencionado, as manifestações sociais de junho de 2013 , tendo, inclusive, sido publicadas na mesma data: 19 de junho de 2013. A escolha de se analisar apenas as primeiras capas foi motivada pelo interesse em compreender como cada publicação escolheu, inicialmente, representar para seus leitores aquele momento histórico que vivia o país - o que poderia revelar distintas perspectivas e ideologias quanto à relevância e à legitimidade do movimento social em questão.

A análise multimodal enfatizou os sentidos construídos pela linguagem verbal e pelas imagens em sua inter-relação. Cada capa foi analisada a partir de cada uma das funções da gramática visual (KRESS; VAN LEEUWEN, 2006). Primeiramente, foram analisados os sentidos representacionais, com vistas à descrição das representações narrativas e/ou conceituais, observando-se quais processos foram construídos por meios dos recursos imagéticos.

Além disso, alguns conceitos propostos pela ACD ajudaram a revelar discursos dominantes subjacentes a tais representações. Com base na descrição dos dados da análise textual multimodal (dimensão textual da ACD), partimos para a interpretação de tais dados em face das práticas discursivas nas quais o texto se insere, dando destaque, por exemplo, para questões de produção, distribuição e consumo. Em seguida, as práticas sociais constitutivas dos textos em análise foram discutidas com o intuito de revelar ideologias e relações de poder constituídas por meio do texto - e também constitutivas desse mesmo texto, tendo-se em vista a relação de bidirecionalidade destacada por Meurer (2005). 
Dessa maneira, cada capa foi analisada individualmente, observando-se os componentes visuais e verbais, bem como a relação entre eles. Ademais, buscando mais elementos textuais que dessem suporte à análise imagética, foi feita a leitura de cada reportagem correspondente - o que nos permitiu associar elementos da microestrutura e da macroestrutura para uma discussão mais aprofundada dos aspectos abordados na análise, a fim de discutir e problematizar a maneira como três dos principais veículos da mídia impressa nacional representaram esse evento histórico em nosso país.

Por fim, os resultados das análises multimodais individuais foram comparados tendo em vista o conjunto de capas escolhidas, traçando-se paralelos entre as representações e os discursos subjacentes. Depois de fazer a análise das capas escolhidas, apresentamos possíveis implicações pedagógicas do trabalho com categorias de análise da Gramática Visual e com conceitos propostos pela ACD. Por fim, fazemos considerações finais sobre a pesquisa desenvolvida.

\section{Análises e Resultados}

Com base nos conceitos teóricos e categorias de análise propostos por Kress e van Leeuwen (2006) para a análise dos sentidos construídos pelas imagens, bem como na discussão das implicações discursivas de tais representações (CHOULIARAKI; FAIRCLOUGH, 1999; FAIRCLOUGH, 2015[1989]; VAN DIJK, 1997; WODAK, 2004), apresentamos, a seguir, as análises das capas das publicações selecionadas.

\subsection{Veja}

Ao analisar a capa da revista Veja, edição 2326 (Fig. 1), com foco nas representações narrativas, percebemos uma questão interessante. Apesar de não haver a representação explícita de um processo narrativo acional, ele pode ser subentendido, visto que alguém teve que atear o fogo que vemos na imagem. Em outras palavras, existe um processo narrativo (acional) anterior à representação.

O fogo, que assume grande destaque na imagem, é, portanto, produto de uma ação realizada pelo(s) PR(s), que também não foram incluídos na imagem. Apenas podemos supor os autores dessa ação ao lermos o texto verbal, que faz referência a jovens revoltados. Fica evidente, portanto, a existência de uma representação que não personifica os reais agentes, para, desta forma, generalizar a ação destruidora como sendo relacionada aos/às jovens em geral. Podemos nos perguntar, assim, os possíveis propósitos de tal representação multimodal, especialmente quando consideramos que esta foi a primeira capa desta publicação abordando esse momento histórico. 


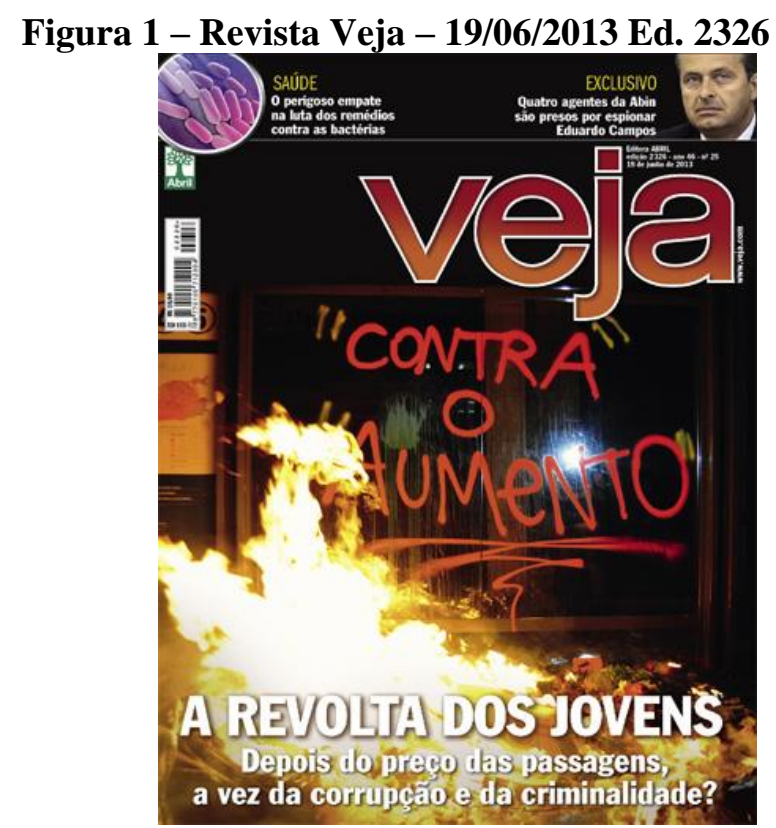

Com foco nas representações conceituais, notamos um processo simbólico sugestivo, representado pela combinação das cores vermelho/laranja e o fogo, expressando a ideia de que tudo está sendo destruído e em chamas - o que conota um estado de manifestações fora do controle. Ainda é possível identificar, a partir da relação entre as cores do plano de fundo preto, do fogo e das cores vermelho/laranja, um clima de obscuridade e tensão - que, aparentemente, refletiria o momento histórico vivido naquele momento.

Em relação aos significados interacionais, há questões relevantes a serem discutidas quanto à distância social, às relações de poder e à atitude. Percebamos, com foco na distância social entre o evento representado e o leitor, que o plano da foto é médio, o que dá a ideia de sociabilidade, ou seja, pode ser compreendido como um fato próximo da realidade atual do leitor. Isso é corroborado pela atitude com o ângulo frontal, que cria envolvimento do leitor com os fatos representados. Com relação às relações de poder, a imagem está no mesmo nível do olhar do leitor, o que implica que há uma relação de paridade entre a posição do leitor e os fatos representados. Os leitores parecem estar sendo chamados a se posicionar sobre as manifestações, visto que as consequências (destrutivas) das mesmas podem alcançá-los a qualquer instante.

A análise composicional desta capa, por sua vez, destaca questões relativas ao valor da informação, ao enquadramento e à saliência. Quanto ao valor da informação, podemos perceber que a frase "CONTRA O AUMENTO" está no centro da imagem estando, assim, em evidência na representação - com os outros elementos da imagem em posição acessória. Além disso, podemos ver que o fogo está em evidência (saliência), a partir de seu posicionamento em primeiro plano, destacando, assim, o resultado das manifestações que esta publicação quis enfatizar. 
Ademais, as aspas podem ser interpretadas como um questionamento, por meio do discurso direto, dos reais motivos para as manifestações em curso. Quem estaria falando nesse texto entre aspas? Em outras palavras, quem está questionando se o aumento da tarifa de transporte urbano foi realmente o motivo para que ocorressem as manifestações de rua? Observe-se, também, que o texto entre aspas parece ter sido escrito à mão, o que acrescenta à ideia de que o questionamento vem das ruas - quando, na verdade, é um questionamento sendo criado de maneira multimodal pela revista.

Questiona-se, assim, se a reação dos/as jovens é proporcional ao descontentamento com o aumento do preço das passagens. Essa ideia de incerteza é ainda reforçada pelo texto da reportagem ao afirmarem que o movimento ainda não estava claro ao que se propunha (MEGALE; RANGEL, 2013).

A pergunta presente na parte inferior da capa também questiona as motivações das manifestações. O fato de não haver modalização na pergunta intensifica o questionamento. Percebemos, também, que o campo semântico no texto verbal é negativo, visto que dá destaque a palavras como revolta, corrupção e criminalidade no contexto nacional, associando-se com os sentidos construídos pela imagem anteriormente discutidos, e.g. destruição e fogo.

Percebamos que, ao utilizar o termo “jovens", a Veja não inclui outras parcelas da população que também participaram das manifestações, como crianças, adultos e idosos. Surge, então, a pergunta: por que não incluir a diversidade populacional que participou das manifestações? Ao focar apenas nos/as jovens, parece haver uma tentativa de deslegitimar as manifestações, pois são ações de jovens revoltados/as que estão causando destruição sem motivo aparente.

De acordo com a matéria publicada por Megale e Rangel (ibid), que desenvolve o tema da capa, esses/as jovens são a minoria, destacando que “(...) essa minoria interessa pouco. Ela será sempre minoria, por definição" (p. 88). Então, se foi uma minoria que causou destruição nas manifestações em questão, por que representar apenas a destruição causada pela minoria na capa? Ainda segundo a reportagem,

O fenômeno realmente espantoso ocorrido na semana passada no Brasil foi o fato de às minorias terem se juntado milhares de rapazes e moças que tinham tudo para estar no cinema, no shopping ou na balada, e não engrossando as fileiras das minorias de vândalos profissionais. A tentação maior é rotulá-los de rebeldes sem causa. (p. 88)

Mostrando apenas a destruição causada durante as manifestações, a capa cria uma representação superficial, possivelmente com o interesse de induzir o leitor a se posicionar de maneira contrária ao movimento social em questão. Ao afirmar que "há uma grande chance de que boa parte da rapaziada (...) esteja apenas dando vazão às pressões hormonais” (p. 86), Megale e 
Rangel (ibid) banalizam qualquer intenção que os/as jovens mencionados/as possam ter para estarem nas ruas, inflamando, assim, a relação do leitor com os participantes das manifestações para que aquele não reconheça a ação destes como legítima. As autoras associam a destruição a jovens revoltados/as recorrendo ao imaginário popular a fim de criar uma ideia equivocada de que jovens não podem estar nas ruas de forma legítima, para, logo em seguida, se contradizerem ao afirmarem que "os jovens, quando vão às ruas protestar, precisam ser ouvidos" (p. 92).

Assim, ao analisarmos a capa da Veja em questão, fica evidente o teor negativo dado às manifestações, tanto pelo texto imagético quanto pelo verbal, questionando-se sua legitimidade. A publicação tenta, portanto, influenciar o leitor para que ele também deslegitime as manifestações e estas percam força. Tal representação destaca o papel constitutivo da linguagem (verbal e imagética) na sociedade, visto que, por meio do discurso multimodal, percebemos como os/as manifestantes devem ser vistos/as pela população a partir da posição de poder que a Veja exerce, ao ser a publicação nacional com maior tiragem.

É importante, portanto, que tenhamos uma postura crítica quanto aos textos que lemos, pois os mesmos sempre estão marcados por questões ideológicas que atendem a interesses específicos, em geral daqueles que detêm a posição hegemônica em determinado momento histórico.

\section{2 Época}

Ao analisar as representações na capa da revista Época edição 786 (Fig. 2), vemos uma representação narrativa com um processo acional não transacional. A imagem traz apenas um participante representado em destaque numa posição de chamada à luta, sendo o vetor formado pelo seu próprio corpo. Contudo, esse participante não pode ser identificado, por ter seu rosto ocultado que se coaduna com o texto verbal em destaque questionando quem são esses/as manifestantes mascarados.

Observamos, ainda, a representação conceitual, por meio de um processo que classifica os participantes como manifestantes, e também um processo simbólico sugestivo caracterizado por cores de tonalidades escuras (cinza e preta). Dessa forma, a imagem sinaliza uma situação sinistra, sombria e tensa. 


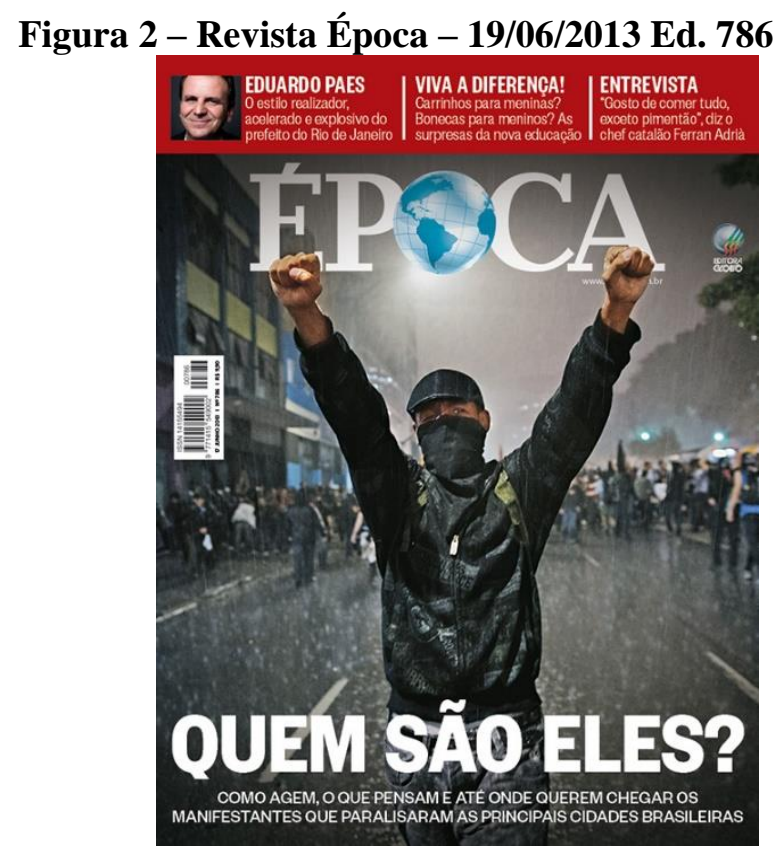

Já a análise da função interacional revela questões relacionadas ao contato, atitude, distância social e relação de poder. Quanto ao contato, percebemos que o olhar do PR está direcionado para o leitor, demandando atenção deste. Isso é corroborado pela atitude, que nos mostra envolvimento do PR com o leitor, que é evidenciada pelo ângulo frontal - que coloca o leitor em posição de conhecer tais manifestantes. Quanto à distância social, temos um plano médio, podendo ser indicativo de que o leitor também poderia estar no mesmo lugar que o PR manifestando por seus direitos - que é ratificado pela relação de poder construída a partir do posicionando do PR em nível de igualdade com o leitor.

$\mathrm{Na}$ análise composicional, por sua vez, encontramos elementos que tratam da informação de valor do tipo ideal/real. A informação ideal é o nome da revista, podendo ser visto como ideal de notícia a ser lida, e também o participante principal representado, visto que ele deve vir a ser conhecido pelo leitor. Já a informação real é o texto verbal, no qual é feita uma pergunta sobre quem seriam essas pessoas que estão se manifestando e o que elas querem. Temos também que o PR está em destaque (saliente) em relação ao restante da imagem devido ao seu posicionamento em foco e em primeiro plano, tendo a multidão em segundo plano.

Tal representação o localiza, talvez, como representante de um grupo de pessoas insatisfeitas com a situação socioeconômica e política do país que decidem se manifestar de maneira mais incisiva nas ruas por meio de ações por vezes destrutivas que acabam por serem qualificadas como de vandalismo. Há que se notar também a relação de composição entre o azul do globo e o azul de partes da rua, criando, assim, uma ideia de que a situação que encontramos nas 
ruas do nosso país também reverbera em outras localidades do planeta, ou, ainda, que no meio de tanta escuridão ainda há esperança por dias melhores (mais coloridos).

Vale salientar que o texto verbal nesta capa é menos explícito, em comparação à capa analisada da Veja, em classificar quem são esses/as manifestantes. Na verdade, o texto verbal convida o leitor a conhecê-los por meio de uma pergunta principal: “Quem são eles?”, em letras grandes e em branco, criando destaque diante do fundo escuro, talvez indicando que esse será o trabalho da revista - revelar para os/as leitores/as quem são essas pessoas e o que elas pretendem ao fazerem parte das manifestações de rua. Pode-se argumentar que, de certa forma, essa representação cria de imediato uma separação entre o público leitor da revista e os/as manifestantes representados ao se supor que eles são completamente desconhecidos - quando, na verdade, são pessoas que estão presentes nas mais diversas camadas sociais (talvez mesmo entre os/as leitores/as dessa revista).

Contudo, é importante ressaltar que, na imagem, temos a representação da parcela mais criticada dos/as manifestantes pela mídia e pelo público em geral: os membros dos Black Blocs. A utilização de um PR com o rosto encoberto cria uma identidade anônima desses indivíduos, já que não sabemos quem são, como agem e o que pensam esses/as manifestantes que paralisaram as principais cidades brasileiras. Tal insegurança e incerteza quanto à identidade desses participantes é intensificada pelo uso das tonalidades preta e cinza em toda a capa. A reportagem correspondente caracteriza esses indivíduos como manifestantes, e não como vândalos (BOMGIG, GORCZESKI, 2013) - que pode ser visto como uma representação menos tendenciosa em comparação com a capa da Veja.

Nessa análise, portanto, podemos observar que a linguagem imagética cria identidade específica para os/as manifestantes, enquanto que o texto verbal convida o leitor a conhecê-los a partir de uma representação mais genérica. A partir da análise de elementos textuais (verbais e não verbais), podemos fazer considerações acerca das representações no nível das práticas discursivas e sociais. É importante destacar, por exemplo, que essa publicação, assim como a Veja e a Época, têm como público-alvo principal a classe média.

É sensato, assim, concluirmos que o discurso presente nessas publicações tente mobilizar essa parte da população para se alinhar aos interesses da classe dominante. Afinal, a quem interessa o incentivo de manifestações sociais que objetivam mudar o status quo a partir de uma reformulação política e da redistribuição mais equânime das riquezas? Vemos, assim, como certas práticas discursivas se alinham com práticas sociais que objetivam a manutenção de relações de poder hegemônicas. 


\subsection{IstoÉ}

Analisando as representações na capa da revista IstoÉ edição 2274 (Fig. 3), há uma representação narrativa por meio de processo acional transacional - que pode ser constatada pela presença de três participantes representados em destaque, envolvidos em ação policial, sendo o vetor formado pelos corpos dos PRs. O policial age em um processo acional transacional unidirecional, o que simboliza a repressão policial e a consequente queda dos/as manifestantes. Já com relação aos outros dois PRs - manifestantes que estão caindo e, aparentemente, se apoiando mutuamente -, temos um processo acional transacional bidirecional. Em outras palavras, o policial os agride unilateralmente e os manifestantes se ajudam. Também percebemos uma representação conceitual a partir de um processo simbólico atributivo, onde o policial com sua farda e seu cassetete está representando a força, a repressão e a autoridade.

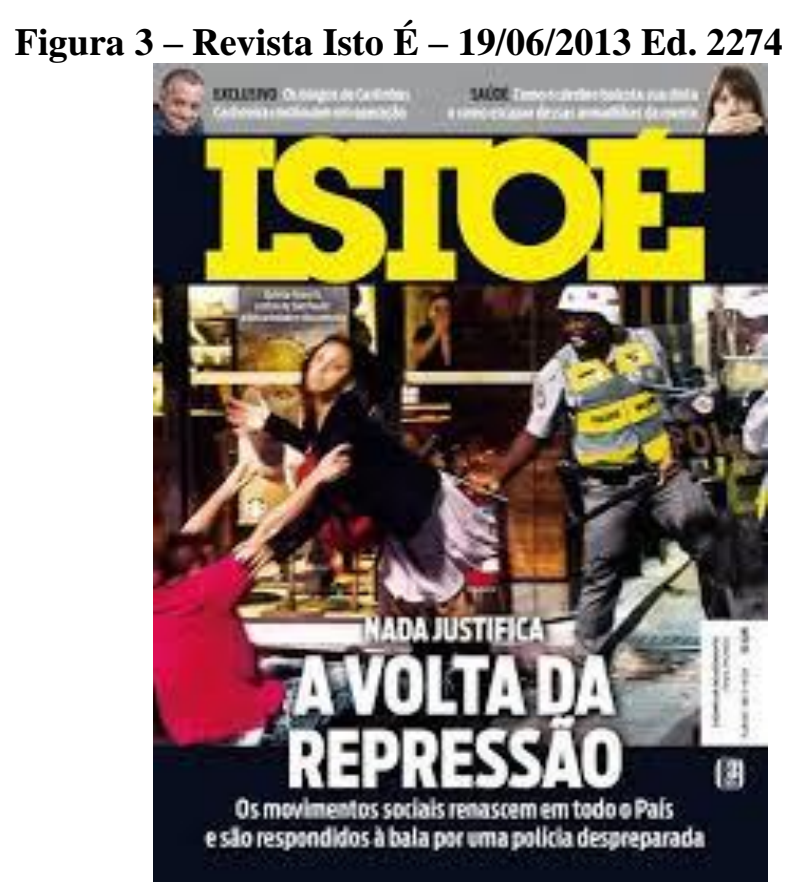

A análise da função interacional, por sua vez, revela aspectos relacionados ao contato, atitude, distância social e poder. O contato ocorre por meio de uma oferta, ou seja, a publicação oferece os PRs apenas para observação do leitor, e não para interação direta. A atitude também nos mostra distanciamento dos PRs do leitor (ângulo oblíquo). Quanto à distância social, temos um plano aberto caracterizando a impessoalidade dos fatos, criando um distanciamento entre o leitor e a ação da polícia. Em relação ao poder, temos que os PRs encontram-se no mesmo nível do olhar do leitor, porém a atitude e distância social revelam o distanciamento que o leitor deve manter das 
manifestações e, consequentemente, da polícia que está nas ruas para repreender de forma violenta tais manifestações.

$\mathrm{Na}$ análise composicional, notamos que os PRs estão em destaque (salientes) em relação ao restante da imagem e que, no plano de fundo, temos uma PR chocada com a ação da polícia. Ademais, temos a informação de valor ideal - centro - real formando um tríptico vertical. Neste caso, a imagem funciona como um mediador entre os valores ideal/real (texto verbal). O texto imagético é mediador entre a credibilidade da revista (ideal) e a informação trazida para os leitores (real) para mostrar um exemplo dessa violência.

O texto verbal, ao afirmar que "nada justifica", condena a ação da polícia, e o verbo "renascer" conota algo positivo. Porém, a resposta "à bala por uma polícia despreparada" atinge de forma violenta o renascimento dos movimentos sociais. Há ainda uma relação de interdiscursividade marcada pela frase "A VOLTA DA REPRESSÃO”, em alusão à ditadura em nossa história recente. Tal construção discursiva enfatiza a fragilidade da imagem da polícia brasileira perante a população, visto que parece não saber lidar com as manifestações de maneira não violenta.

Ao observamos a imagem, é possível perceber a força, raiva e violência com que o policial ataca os manifestantes. De certa forma, a IstoÉ legitima os movimentos sociais que renascem nesse momento histórico ao condenar a ação violenta da polícia - que é percebido tanto nos elementos verbais quanto nos imagéticos. Assim, essa capa da IstoÉ faz uma crítica à ação repressora e autoritária da polícia durante os movimentos sociais que ressurgem em todo o País. Com isso, podemos dizer que a publicação denuncia práticas sociais de uma classe dominante que tenta por meio da força manter a ordem. Tal interpretação é ainda balizada pelo que o autor da reportagem fala ao afirmar que os "manifestantes de movimentos sociais voltam às ruas das grandes capitais e são reprimidos com uma truculência injustificável e desproporcional, que não é vista desde os tempos da ditadura" (LEITE, 2013, p. 103).

\subsection{Visão Geral das Três Revistas}

Comparando as três publicações analisadas, alguns paralelos podem ser traçados. Uma visão geral da análise da capa da revista Veja revela que a publicação tenta deslegitimar as manifestações ocorridas em todo o país ao focar apenas na destruição causada pela minoria dos/as manifestantes que fazia parte de determinado grupo. Já na análise da capa da revista Época, percebemos que a publicação tenta 'desmascarar' os/as manifestantes que tomaram conta das principais cidades do país a fim de entender o que querem esses/as jovens. Por sua vez, a publicação 
da revista IstoÉ parece legitimar as manifestações, criticando a ação da polícia e evidenciando o poder que o cidadão brasileiro tem de fazer com que a política funcione em prol da sociedade.

Do ponto de vista interacional, a revista Veja coloca o leitor numa posição de sociabilidade, a partir da qual toma conhecimento dos fatos que estão ocorrendo em seu entorno e, de certa forma, convida-o a se posicionar sobre as manifestações. Na publicação da revista Época, ocorre, também, a questão da sociabilidade, porém é demandada do leitor atenção para conhecer os/as manifestantes e as suas insatisfações. A publicação da revista IstoÉ, por sua vez, cria uma relação de impessoalidade entre o leitor e os fatos representados na imagem, possivelmente para que o leitor se distancie das manifestações devido ao perigo de serem vítimas de ações policiais violentas.

Quanto à análise da composição, a Época e a IstoÉ trazem a informação de valor no parâmetro ideal/real nas suas capas. No campo ideal, geralmente temos o nome da revista, o que pode ser entendido como o ideal de notícia a ser lida pelo leitor, enquanto que, no campo real, temos as informações verbais que estão sendo veiculados pelas publicações representando os eventos a partir de determinada perspectiva.

Diante do exposto, é possível aferir que a revista Veja cria a identidade de jovens revoltados/as ao focar na ação da minoria presente nas manifestações revelando o poder constitutivo da linguagem. Podemos dizer, também, que, ao tentar atribuir um grau maior ou menos de legitimidade às manifestações, essas publicações parecem influenciar o leitor a fazer o mesmo, já que o discurso influencia e é influenciado por quem o lê (FAIRCLOUGH, 2015[1989]; WODAK, 2004).

\section{CONSIDERAÇÕES FINAIS}

Diante da importância social, cultural e política dos protestos que ocorreram em 2013 no Brasil, a análise das relações de poder estabelecidas a partir das representações construídas nas capas das três revistas (Veja, Época e IstoÉ) de maior circulação no país mostra-se particularmente relevante - especialmente quando consideramos que os textos multimodais são ferramentas poderosas para criar significados e construir visões da realidade (NASCIMENTO; BEZERRA; HEBERLE, 2011).

Sendo assim, à luz da teoria da gramática visual (KRESS; VAN LEEUWEN, 2006) e da ACD (FAIRCLOUGH, 2015[1989]), desvendamos sentidos construídos com o intuito de compreender alguns discursos dominantes que se fizeram presentes durante esse momento histórico. Estabelecemos como o uso da linguagem verbal e das imagens em composições multimodais pode ocultar sentidos que, muitas vezes, são apenas inconscientemente apreendidos por meio da repetição 
de certas representações em nosso cotidiano. Ademais, revelamos a curva ideológica informada pela política editorial de cada uma das três publicações, que pode ser compreendida a partir da comparação entre as capas e, destacadamente, da leitura das matérias correspondentes a fim de dar maior credibilidade às análises desenvolvidas nesta pesquisa, visto que a análise de elementos microestruturais também deve ser reforçada pela inclusão de considerações da macroestrutura em que tais textos se inserem.

Como conclusão principal, destacamos que as três publicações analisadas, por meio da integração entre o texto verbal e a imagem, criam identidades, mantêm e/ou criam relações de poder, perpetuam práticas sociais e ideologias. Percebemos isso, por exemplo, na análise da função composicional, em que os elementos imagéticos são cuidadosamente selecionados para representar o ponto de vista dos autores e, assim, influenciar o leitor a deslegitimar as manifestações.

Outra questão importante é o posicionamento dado ao leitor com relação aos fatos veiculados. Esse efeito é conseguido através de algumas estratégias, dentre as quais destacamos a distância social e atitude, que colocam o leitor em uma posição particular, necessária para o grau de distanciamento pretendido pelos autores a fim de que aquele não participe das manifestações. Ademais, os participantes representados são mostrados despersonalizados ou com a face coberta, o que interpretamos como uma estratégia das edições para diminuir a possibilidade de os leitores se identificarem com tais manifestantes.

Sendo assim, podemos concluir que, para atuar criticamente na sociedade contemporânea, o trabalho integrado entre o texto verbal e visual deve ser desenvolvido visando a formar indivíduos conscientes do seu papel no meio em que vivem (BEZERRA, 2016). Nesse sentido, destacamos o importante papel da escola em oferecer uma "alfabetização crítica da mídia” (KELLNER; SHARE, 2008). Por conseguinte, é importante que esses/as alunos/as sejam preparados/as para ler os textos multimodais que os/as cercam no dia a dia, desenvolvendo sua "competência comunicativa multimodal" (ROYCE, 2007; HEBERLE, 2010), visto que tais textos estão imbuídos de discursos e ideologias diversas que, muitas vezes, servem para manter o status quo e relações de dominação.

\section{REFERÊNCIAS}

BEZERRA, Fábio. Multiletramentos na sala de aula de língua estrangeira. In: OUVERNEY-KING, Jamylle; COSTA FILHO, José (Orgs.), Reflexões didáticas sobre o ensino de língua estrangeira na atualidade. João Pessoa: IFPB, 2015, p. 71-90.

. A análise crítica do discurso e os multiletramentos: o papel da linguagem no fazer docente contemporâneo. In: NÓBREGA, Carmem; ARCOVERDE, Rossana; BRANCO, Sinara e FARIAS, 
Washington (Orgs.), Educação linguística e literária: discursos, políticas e práticas. Campina Grande: UFCG, 2016, p. 189-204.

; NASCIMENTO, Roseli; HEBERLE, Viviane. Análise multimodal de anúncios do programa 'Na Mão Certa'. Revista Letras (UFSM), Santa Maria, v. 20, n. 40, p. 9-26, 2010.

BOMBIG, Alberto; GORCZESKI, Vinicius. Quem são os manifestantes que pararam as grandes cidades do país. Época, São Paulo, edição 786, jun. 2013. Disponível em: <http://revistaepoca.globo.com/Sociedade/noticia/2013/06/quem-sao-os-manifestantes-quepararam-grandes-cidades-do-pais.html>. Acesso em: 25 ago. 2014.

CALDAS-COULTHARD, Carmen. Da análise do discurso à análise crítica do discurso: Introduzindo conceitos. In: CALDAS-COULTHARD, Carmen; SCLIAR-CABRAL, Leonor (Orgs.), Desvendando discursos: Conceitos básicos. Florianópolis: Ed. da UFSC, 2008, p. 19-44.

CHOULIARAKI, Lilie; FAIRCLOUGH, Norman. Discourse in late modernity: rethinking critical discourse analysis. Cambridge: Polity Press, 1999.

FAIRCLOUGH, Norman. Discourse and social change. Cambridge: Polity Press, 1992a.

. Critical language awareness. London: Routledge, 1992b.

Media discourse. Edward Arnold, 1995a.

. Critical discourse analysis. London: Longman, $1995 \mathrm{~b}$.

. Language and power. London: Longman, 2015[1989].

HALLIDAY, Michael; MATTHIESSEN, Christian. An introduction to functional grammar. 3. ed. Londres: Hodder Arnold, 2004.

HERBELE, Viviane. Multimodal literacy for teenage EFL students. Cadernos de Letras (UFRJ), n. 27, p. 101-116, 2010.

KELLNER, Douglas. Media culture: cultural studies, identity and politics between the modern and the postmodern. Londres, Nova York: Routledge, 2003.

; SHARE, Jeff. Educação para a leitura crítica da mídia, democracia radical e a reconstrução da educação. Educ. Soc., v. 29, n. 104 (Especial), p. 687-715, 2008.

KRESS, Gunther; VAN LEEUWEN, Theo. Reading images: the grammar of visual design. Londres, Nova York: Routledge, 2006.

LEITE, Paulo. Do sonho ao vandalismo e à brutalidade. IstoÉ, São Paulo, edição 2274, jun. 2013. Disponível em:

<http://www.istoe.com.br/reportagens/307104_DO+SONHO+AO+VANDALISMO+E+A+BRUT ALIDADE>. Acesso em: 25 ago. 2014.

MAGALHÃES, Izabel. Introdução: a análise de discurso crítica. D.E.L.T.A., 21: Especial, p. 1-9, 2005. 
MEGALE, Bela; RANGEL, Carolina. A razão de tanta fúria. Veja, São Paulo, edição 2326, p. 8492, jun. 2013. Disponível em: 〈http://veja.abril.com.br/acervodigital/home.aspx >. Acesso em: 25 ago. de 2014.

MEURER, José. Gêneros textuais na análise crítica de Fairclough. In: MEURER, José; BONINI, Adair; MOTTA-ROTH, Désirée. (Orgs.), Gêneros: teorias, métodos, debates. São Paulo: Ed. Parábola Editorial, 2005, p. 81-106.

NASCIMENTO, Roseli; BEZERRA, Fábio; HEBERLE, Viviane. Multiletramentos: iniciação à análise de imagens. Linguagem e Ensino, v. 14, n. 2, p. 529-552, 2011.

PROCÓPIO, Renata; SOUZA, Patrícia. Letramento visual no ensino-aprendizagem de vocabulário em língua estrangeira. The Especialist, v. 31, n. 1, p. 93-118, 2010.

ROJO, Roxane. Letramentos Múltiplos, escola e inclusão social. São Paulo: Parábola Editorial, 2009. 2012.

; MOURA, Eduardo. (Orgs.). Multiletramentos na escola. São Paulo: Parábola Editorial,

ROYCE, Terry. Multimodality in the TESOL classroom: exploring visual-verbal synergy. TESOL Quarterly, v. 36, n. 2, p. 191-205, 2002.

. Multimodal communicative competence in second language contexts. In:

BOWCHER, Wendy (Orgs.), New directions in the analysis of multimodal discourse. Mahwah, NJ: Lawrence Erlbaum, 2007, p. 361-403.

STHEPHANOWITZ, Helena. Sem alarde da mídia, Alckmin renova 5,2 mil assinaturas da Veja. Rede Brasil Atual. Disponível em: <http://www.redebrasilatual.com.br/blogs/helena/2013/08/semalarde-da-midia-alckmin-renova-5-2-mil-assinaturas-daveja-2556.html > Acesso em: 25 ago. de 2014.

VAN DIJK, Theo. Discourse as interaction in society. In: VAN DIJK, T. A. (Org.), Discourse as social interaction. Londres, Thousand Oaks, Nova Deli: Sage, 1997, p. 1-37.

VAN LEEUWEN, Theo. Introducing social semiotics. Londres, Nova York: Routledge, 2005.

WODAK, Ruth. Do que trata análise crítica do discurso - um resumo de sua história, conceitos importantes e seus desenvolvimentos. Linguagem em (dis)curso - LEMD, Tubarão, v. 4, n. esp., p. 223-243, 2004. 